Research Article

\title{
Fabrication of Polypropylene-g-(Diallylamino Triazine) Bifunctional Nonwovens with Antibacterial and Air Filtration Activities by Reactive Extrusion and Melt-Blown Technology
}

\author{
Chao Liu $\mathbb{D}^{1},{ }^{1,2}$ Zijian Dai ${ }^{D},{ }^{1}$ Rong Zhou $\left(\mathbb{D},{ }^{2}\right.$ Qinfei Ke $\mathbb{D}^{1},{ }^{1}$ and Chen Huang ${ }^{1}{ }^{1}$ \\ ${ }^{1}$ Key Laboratory of Textile Science \& Technology of Ministry of Education, College of Textiles, Donghua University, \\ Shanghai 201620, China \\ ${ }^{2}$ Textile and Fashion Collage, Hunan Institute of Engineering, Xiangtan 411101, China
}

Correspondence should be addressed to Qinfei Ke; kqf@sit.edu.cn and Chen Huang; hc@dhu.edu.cn

Received 26 September 2019; Accepted 15 November 2019; Published 4 December 2019

Academic Editor: José M. G. Martinho

Copyright (c) 2019 Chao Liu et al. This is an open access article distributed under the Creative Commons Attribution License, which permits unrestricted use, distribution, and reproduction in any medium, provided the original work is properly cited.

Air filtration materials such as protective masks can protect humans from airborne pathogens; however, most of the existing protective filtration materials are aimed to intercept bacteria. Therefore, in this work, modified polypropylene- (PP-) based meltblown nonwovens with antibacterial property were prepared for reducing the infection rate during the filtering process. Firstly, an $\mathrm{N}$-halamine precursor, 2,4-diamino-6-diallylamino-1,3,5-triazine (NDAM) monomer, was grafted with PP polymers (PP-gNDAM) by reactive extrusion method, and the grafting effect was confirmed by nitrogen analysis and FTIR spectra. Then, the obtained PP-g-NDAM was mixed with pristine PP resins in different ratios to prepare the filter materials by melt-blown technology. Finally, the new PP-g-NDAM melt-blown filter materials were finishing treated by the chlorination and electrostatic process, which showed a high filtration efficiency with low pressure drop and a potent antibacterial effect against Escherichia coli (E. coli). This work provides an innovative method for manufacturing antibacterial filtration nonwovens, which can improve the quality of conventional filtration products.

\section{Introduction}

Human beings unavoidably expose themselves to airborne pathogens in daily lives; it is noted that the pathogens will propagate and spread in conditions of suitable temperature and humidity, which poses a serious risk of respiratory disease to human health. At present, using air filtration media is the most effective way to protect people from the influences of airborne pathogens. However, most of the fiber-based filters only focused on particulate matter (PM) removal, and the majority of pathogens are controlled by the retention on the fiber surface, instead of cleaning them out, resulting in a potential health concern of the secondary infection. Therefore, there is an urgent requirement for fabricating multifunctional filter materials with antibacterial and air filtration properties, which could improve the protective effect.
Polypropylene (PP) materials have been intensively used in face masks, air purifiers, protective suit, surgical gown, and hygienic products, where antimicrobial functions are highly desired. Because of the excellent chemical stability, antibacterial modifications of PP materials are relatively difficult to conduct. In the past decades, researchers have used the methods of surface grafting [1-3] or surface coating [4] of antimicrobial agents onto PP polymer materials to achieve antibacterial functions, however, with limited durability and applications. Besides, once the antimicrobial agents are entirely consumed, the antimicrobial property cannot be regenerable anymore [5-7]. To solve the problem mentioned above, $\mathrm{N}$-halamines [8-12] were selected as an ideal antibacterial agent to modify PP polymers, which has advantages of broad-spectrum and long-term sterilization activity, durable, regenerable, stability, safe to human, and environmental friendly $[13,14]$. Sun et al. [15-18] have 
developed $N$-halamine-modified polymers by grafting method, and it is found the method has been well studied due to the short reaction time, continuous production, and easy industrialization $[19,20]$. The modified polymers were then fabricated into nanofibers with the diameter ranging from 100 to $550 \mathrm{~nm}$ through an immiscible blending extrusion process and exhibited powerful antibacterial properties. Because of the tedious fabrication process and exceptionally high filtration resistance, the application prospect is limited.

Hitherto, PP melt-blown nonwovens are widely used as filter materials because of their high surface area, small pore size distribution, high filtration efficiency, and low pressure drop [21]. Moreover, PP melt-blown technology has the advantages of high output, low cost, and short process [22]. The overall propose of this study was to develop a bifunctional melt-blown fiber filter combining antibacterial and air filtration abilities. Herein, an $\mathrm{N}$-halamine precursor, 2,4-diamino-6-diallylamino-1,3,5-triazine (NDAM), was grafted onto $\mathrm{PP}$ using reactive extrusion, and the grafting effect of PP-g-NDAM polymers was characterized by approaches of nitrogen analysis, Fourier transform infrared spectroscopy (FTIR), and thermogravimetric analysis (TG). Then PP-g-NDAM resins were fabricated into nonwovens by melt-blown technology. After chlorination of the asprepared nonwovens that converted the halamine precursor structures to antibacterial moieties, and corona charging treatment, the new PP-g-NDAM melt-blown filter materials showed a high filtration efficiency with low pressure drop and a potent antibacterial effect against Escherichia coli (E. coli) after short contact times, which has the potential and promising application capabilities in the filtration industry.

\section{Materials and Methods}

2.1. Materials. Polypropylene resins (PP, melt flow index: 1500) were purchased from Dawn Co. (Shandong Province, China), 2,4-diamino-6-diallylamino-1,3,5-triazine (NDAM) monomer was obtained from TCI (Portland, OR), and dicumyl initiator (DCP) was obtained from China National Pharmaceutical Group Co. (Beijing, China). Acetone and toluene were used in the purification process, sodium hypochlorite was used for chlorination, and potassium iodide and sodium thiosulfate were used to titrate the active chlorine content. All chemicals used in this research were purchased from China Chemical Reagent Company and employed without further purification.

2.2. Synthesis of PP-g-NDAM Polymer. The PP-g-NDAM polymer was produced by grafting the PP with NDAM monomers using reactive extrusion. As shown in Figure 1, the PP resins used in this study were predried in an incubator at $60^{\circ} \mathrm{C}$ for $12 \mathrm{~h} .100 \mathrm{~g}$ of PP was thoroughly mixed with different amounts of NDAM monomer (i.e., 8, 9, and $10 \mathrm{~g}$ ) and DCP initiator (i.e., 0.4, 0.5, 0.6, and $0.7 \mathrm{~g}$ ). All reactants were dry-mixed together for $20 \mathrm{~min}$ and then poured fast $(<10 \mathrm{~s})$ into a twin-screw extruder (Model MIC 18/GL 30D, Nurnberg, Germany). The feeding and screw speeds were controlled as $20 \mathrm{rpm}$ and $30 \mathrm{rpm}$, respectively. The temperatures of the screw extruder from feeder to the extrusion were set as $150,165,170,175,180,175$, and $160^{\circ} \mathrm{C}$, respectively. After the reaction is done, the as-prepared polymeric streams were frozen in a cooling water bath and were granulated into particles with a length of less than $10 \mathrm{~mm}$.

In the initial stage of the melt graft polymerization, the peroxide initiator DCP thermally decomposed to initial radicals after entering the twin-screw extruder, which could capture the hydrogen atoms from the tertiary carbon atoms of the PP polymer backbone to form PP macromolecular radicals. Part of the macromolecular radical could initialize the grafting polymerization of NDAM monomer onto the backbones to create desired grafted PP. And the other part undergoes $\beta$-scission to form secondary radicals, which can still react with monomers [23], as shown in Scheme 1 . Moreover, when the initial monomer concentration increased, this NDAM monomer that grafted onto PP backbones may react with more monomer molecules, and such a process may contribute to longer chain branches in PP molecules [24].

2.3. Preparation of Melt-Blown Nonwovens. Generally, the fiber webs manufactured by $100 \mathrm{wt} . \%$ grafted PP showed a tough hand feeling. Based on this concern and in order to improve the quality of the melt-blown nonwovens, the asprepared PP-g-NDAM with the highest grafting efficiency was selected to mix with the pristine PP at different weight ratios (i.e., the weight percentage of the PP-g-NDAM was set to 0 wt. $\%, 40$ wt.\%, 70 wt.\%, and 100 wt.\%). Then, the PP-gNDAM/PP mixtures were extruded into the melt-blown device (see Figure 2). During the melt-blown process, the solid PP-g-NDAM/PP resins were firstly supplied into the screw extruder through a hopper, and the resin was gradually melted by the treatment of the heating screw and extruded out through the polymer orifice. Then, the extruded polymer stream was attenuated into microfibers by the high-velocity hot air. In the meantime, the same air streams deliver the fiber to the collector, and the bonding took place at the fiber-tofiber contact points. Finally, the fibers were cooled at room temperature to form the nonwoven. The technological parameters applied in the melt-blown process were set as follows. The length-to-diameter ratio of screw extruder was 35 : 1 , and the screw extruder was heated in six separately regions; correspondingly, the temperature of the six parts of the screw extruder were maintained to $190,200,215,220,220$, and $225^{\circ} \mathrm{C}$. It is equal to that the temperature of the extruded polymer melt was $225^{\circ} \mathrm{C}$. Air with a pressure of $0.4 \mathrm{MPa}$ and a temperature of $235^{\circ} \mathrm{C}$ was applied to the melt-blown spinneret. For the structure of the spinneret, the apex angle of the air plates was $60^{\circ}$, and the diameter of the polymer orifice was $0.5 \mathrm{~mm}$. All the microfibrous nonwovens were collected on the rotating roller, and the minimum die-to-collector distance (DCD) was $300 \mathrm{~mm}$.

Notably, to improve the filtration performance of the melt-blown nonwovens, corona charging treatment was commonly applied to eject electrostatic charges into the 


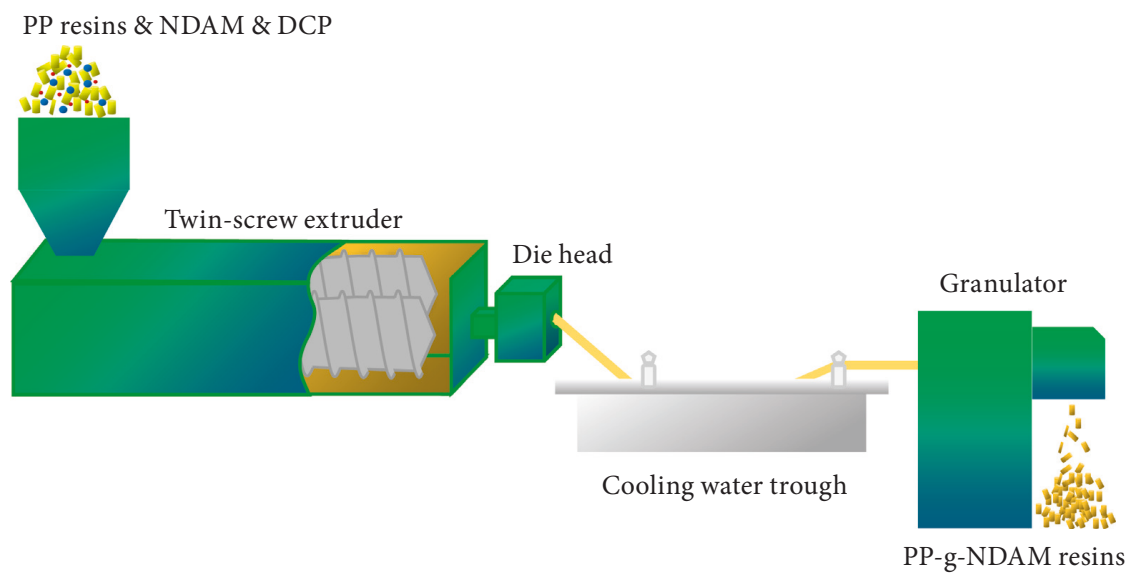

FIGURE 1: Schematic diagram of the reactive extrusion process and granulation of NDAM monomers grafted onto PP polymers.

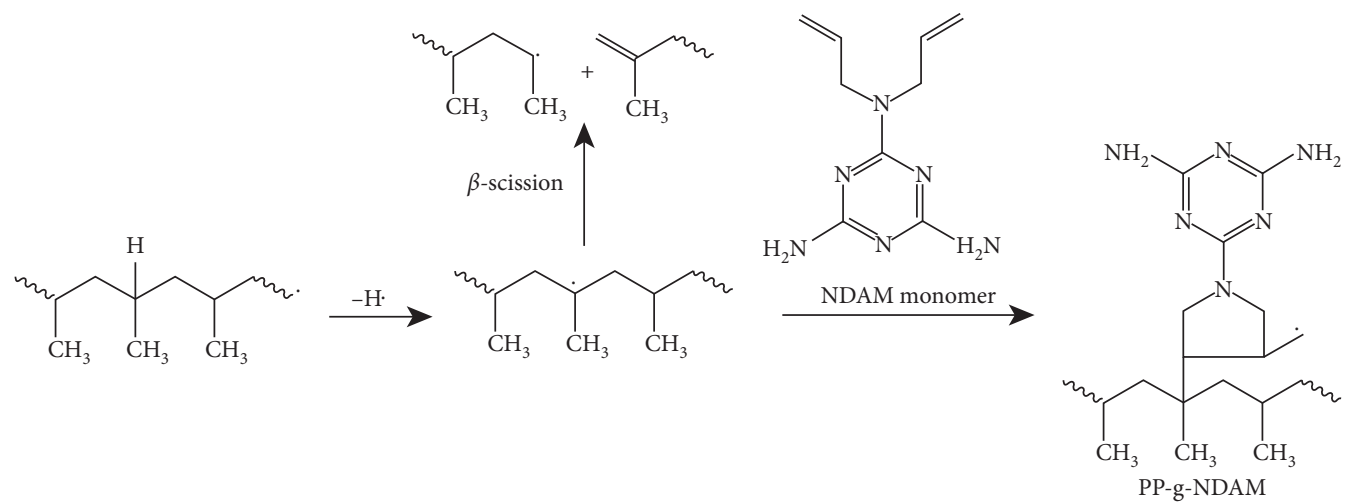

Scheme 1: Grafting reaction of PP with NDAM in the reactive extrusion process.

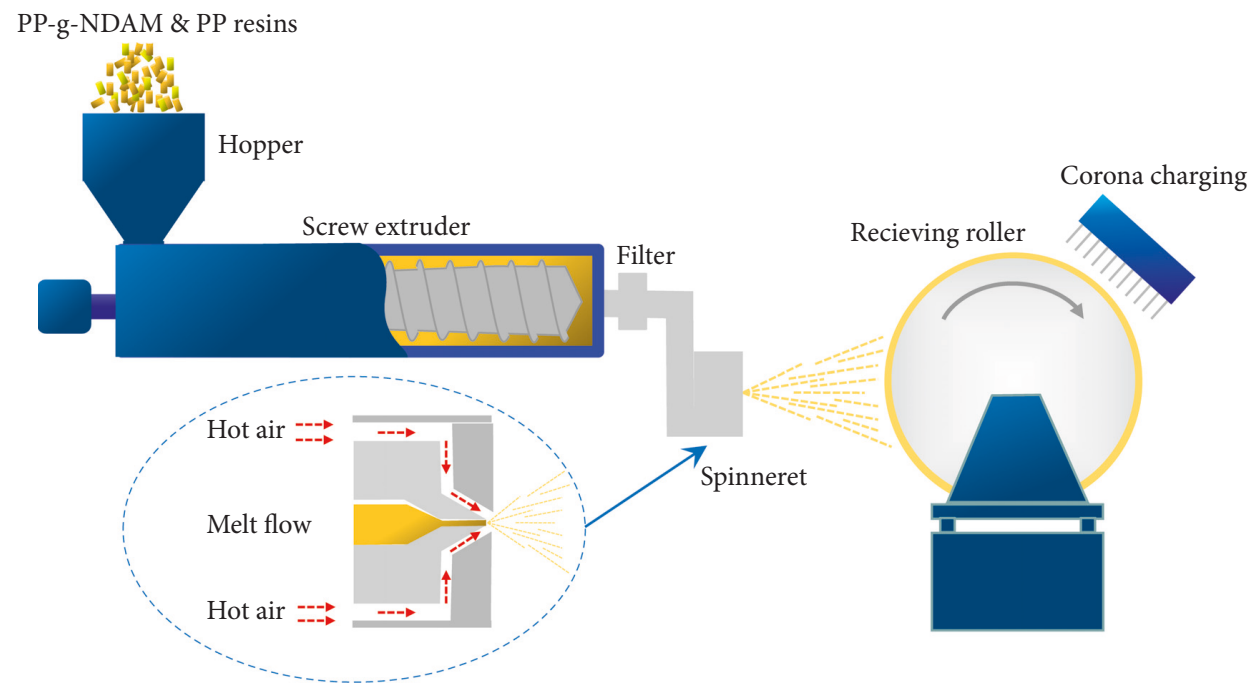

FIGURE 2: Schematic diagram of the grafted PP melt-blown nonwovens process.

polymeric fibers. Electret melt-blown nonwovens have been proved to be a desired material to filtrate fine particulate matter due to the electrostatic force, which can significantly increase the filtration efficiency without increasing the pressure drop. The corona charging apparatus used in this study has been described in detail in the previous paper [25]. Briefly, it consists of a high-voltage power supplier, an array of needles, and a copper holder. The as-prepared nonwovens were placed $10 \mathrm{~cm}$ underneath the copper holder to charge for $30 \mathrm{~s}$ under a high voltage of $18 \mathrm{kV}$. 
2.4. Antibacterial Treatment of Melt-Blown Nonwovens. The anticipated antibacterial properties were carried out by the chlorination reaction, which can change the $-\mathrm{NH}_{2}$ to -NHCl. Refer to the process of chlorination reaction, the PPg-NDAM melt-blown nonwovens were immersed in dilute chlorine bleach (ca. $2500 \mathrm{mg} / \mathrm{L}$ available chlorine) for $1 \mathrm{~h}$ at room temperature, and the $\mathrm{pH}$ was adjusted to 7 by diluted sulfuric acid. Then, the melt-blown nonwovens were washed thoroughly with excess amounts of distilled water and dried at $40^{\circ} \mathrm{C}$ for $6 \mathrm{~h}$. As shown in Figure 3, the antibacterial properties of the PP-g-NDAM melt-blown nonwovens were endowed by the active chlorine with highly oxidizing. The active chlorine has the function of destroying or inhibiting the metabolic process of bacteria $[26,27]$. It was noted that this antibacterial process accompanied by the reversed conversion of $-\mathrm{NHCl}$ into $-\mathrm{NH}_{2}$. However, the antibacterial properties of the PP-g-NDAM melt-blown nonwovens could be rechargeable by the repeated chlorine bleaching process $[28,29]$.

2.5. Grafting Effect Measurements. As described in Scheme 1, during the grafting process, the NDAM monomer was successfully grafted onto PP backbones. In order to remove the unreacted NDAM monomers, $2 \mathrm{~g}$ of the PP-g-NDAM resins was dissolved in $50 \mathrm{~mL}$ of hot toluene for $30 \mathrm{~min}$, and then the hot solution was dropped into $200 \mathrm{~mL}$ of acetone at room temperature. The precipitated PP-g-NDAM powders were subsequently separated by filtration and washed several times with acetone. Finally, the as-received PP-g-NDAM powders were dried in a vacuum oven at a temperature of $60^{\circ} \mathrm{C}$ for $12 \mathrm{~h}$.

The grafting effect was then determined by FTIR, TGA, and nitrogen elemental analysis. As a control group, the pristine PP resins were also used for such measurements.

The FTIR was used to characterize the functional groups of the materials. The samples and the potassium bromide powder were mixed and compressed into pellet to be analyzed by Bruker Tensor 27 Spectrometer in TR mode. The spectral range is from 400 to $4000 \mathrm{~cm}^{-1}$ with $4 \mathrm{~cm}^{-1}$ resolution, and the scanning times were $64 \mathrm{~cm}^{-1}$.

TGA (NETZSCH model 209 F1) was applied to test the thermal properties of the materials. The testing was performed by heating samples up to $600^{\circ} \mathrm{C}$ with a heating rate of $10^{\circ} \mathrm{C} /$ min under a steady nitrogen flow.

Vario EL III (Elementar, Germany) elemental analyzer was also used to characterize the grafting level. The analyzer comprises a combustion section, a thermal conductivity cell detection system, and a data analysis system. The materials used for testing were entirely burned and decomposed at high temperature, where composition elements were converted into their oxidation state. The mixed gas carried by helium gas enters the adsorption and desorption column; after that, the gas components were separated and the content of $\mathrm{N}$ in the sample was continuously detected by a thermal conductivity detector (TCD). Since the nitrogen content was obtained, the grafting degree (GD) and grafting efficiency (GE) were calculated from equation (1) and (2):

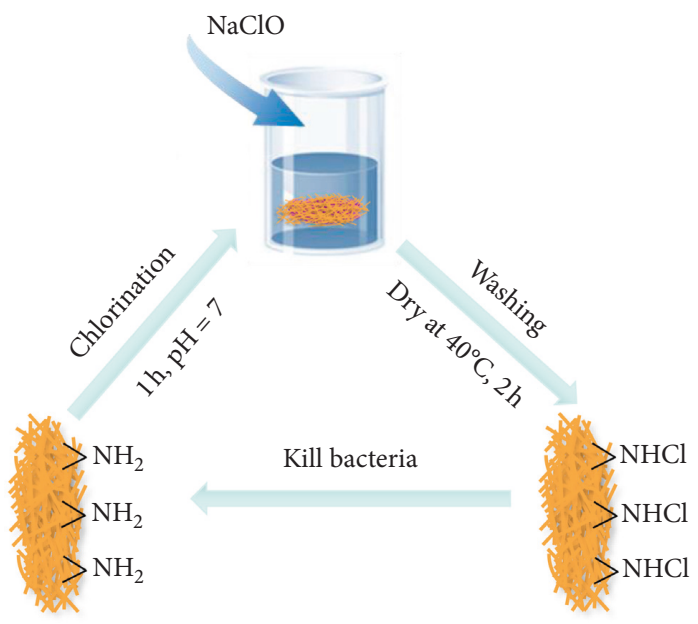

Figure 3: Simplified illustration of chlorination and antibacterial mechanism of the grafted melt-blown nonwoven.

$$
\mathrm{GD}=\frac{C_{\mathrm{N}}}{C_{\mathrm{N}}^{\prime}} \times \frac{M_{\mathrm{PP}}}{M_{\mathrm{PP}}+M_{\mathrm{DCP}}+M_{\mathrm{NDAM}}} \times 100 \%,
$$

where $C_{\mathrm{N}}$ is the nitrogen content (wt.\%) of the grafted sample and $C_{\mathrm{N}}^{\prime}$ is the nitrogen content (wt.\%) of the NDAM monomer. $M_{\mathrm{PP}}, M_{\mathrm{DCP}}$, and $M_{\mathrm{NDAM}}$ are the weight of reactants (g).

$$
\mathrm{GE}=\frac{M_{\mathrm{NDAM}}^{\prime}}{M_{\mathrm{NDAM}}} \times 100 \%,
$$

where $M_{\text {NDAM }}^{\prime}(\mathrm{g})$ is the weight of the grafted NDAM in the products. $M_{\text {NDAM }}(\mathrm{g})$ is the amount of NDAM monomers used in the grafting polymerization.

2.6. Melt-Blown Nonwoven Structure and Filtration Efficiency (FE) Measurements. Surface morphology of the melt-blown nonwovens was observed by using JEOL, JSM-IT300A analytical scanning electron microscope (SEM) after a thin AU-Pd layer was sputter-coated on samples. The fiber diameter was measured by the Image-Pro Plus software. The average diameter was calculated by at least 100 measured diameters. Moreover, the pore size of the melt-blown nonwovens was characterized by a capillary flow porometer (CFP-1100AI, Porous Materials Inc., USA) based on the bubble point test.

The filtration efficiency (FE) of melt-blown nonwovens was tested by an automatic filter tester (Model 8130, TSI Inc., USA), which can generate sodium chloride $(\mathrm{NaCl})$ aerosol with a mean particle size of $0.26 \mu \mathrm{m}$ at the geometric standard deviation of 1.86. The particle size distribution of the aerosol ranges from $0.1 \sim 2 \mu \mathrm{m}$. The aerosol particles passed through the samples with a valid test area of $100 \mathrm{~cm}^{2}$ at the flow rate of $85 \mathrm{~L} / \mathrm{min}$. Each sample was tested three times to reduce random error. The air pressure drop for the nonwovens was measured by a flow gauge and two electronic pressure transmitters. Filtration efficiency (FE) was calculated as follows: 


$$
\mathrm{FE}(\%)=\left(1-\frac{C_{\mathrm{d}}}{C_{\mathrm{u}}}\right) \times 100,
$$

where $C_{\mathrm{d}}$ is the aerosol concentration of the downstream side of the respirator filter and $C_{\mathrm{u}}$ is the concentration of the challenge aerosol of the upstream side.

2.7. Active Chlorine Content Measurement. As shown in Figure 3, the anticipated antibacterial properties were carried out by converting the $-\mathrm{NH}_{2}$ to $-\mathrm{NHCl}$. Therefore, the active chlorine content was an indicator for quantifying the antibacterial effect. It was verified that even the polymer materials contained a tiny amount of $0.2 \mathrm{wt} . \%$ active chlorine. It still shows a strong bactericidal property [30]. The active chlorine content was measured by the method of iodometric/thiosulfate titration. Around $0.15 \mathrm{~g}$ of the material was weighed and then mixed with $5 \mathrm{~mL}$ of deionized water, $0.2 \mathrm{~g}$ of potassium iodide, and $1 \mathrm{~mL}$ of $0.5 \%$ starch solution. Initially, due to the starchy environment, the solution exhibited a dark blue color when touched with the titrated iodine. The sodium thiosulfate solution was continuously titrated until the dark blue color disappeared. Meanwhile, the volume of sodium thiosulfate solution used in titration was recorded. Each PP-g-NDAM melt-blown nonwoven was titrated three times under the same experimental conditions. The weight ration of the chlorine content $\left(\mathrm{Cl}^{+} \%\right.$ ) can be determined by the following equation:

$$
\mathrm{Cl}^{+} \% 0=\frac{35.45 \times N \times V}{2 \times W} \times 1000,
$$

where $\mathrm{Cl}^{+} \%$ is the weight percentage of available active chlorine of the samples, $N$ and $V$ are the normality (equiv./L) and volume $(\mathrm{L})$ of the titrant sodium thiosulfate, respectively, and $W$ is the weight of the grafted PP melt-blown material (g).

In order to investigate the regenerability of the bactericidal functional group of $-\mathrm{NHCl}$ bond in the grafted meltblown nonwoven, around $0.15 \mathrm{~g}$ of the nonwovens was soaked in sodium thiosulfate solution for $30 \mathrm{~min}$ to conduct a simulation study of the loss of - $\mathrm{NHCl}$ bond during sterilization. Then, the materials were washed and dried, and the - $\mathrm{NHCl}$ bond could be regenerated by soaking the material in dilute chlorine bleach in $1 \mathrm{~h}$. After repeating the reduction and chlorination working cycles by 10 times, the active chlorine content was measured by iodometric/thiosulfate titration.

2.8. Antibacterial Property Measurement. The antibacterial properties of the chlorinated grafted melt-blown nonwovens were examined by the sterilization experiment referring to $E$. coli (K-12, a Gram-negative bacterium). This experiment was under the standard of the AATCC test method 1001999. Pristine PP melt-blown nonwoven was used for a blank experiment. The melt-blown nonwovens were cut into small pieces $(4 \times 4 \mathrm{~cm})$, and two swatches of the grafted PP melt-blown nonwovens were placed in a sterilized container. $1 \mathrm{~mL}$ of $E$. coli suspension containing $10^{5} \sim 10^{6}$ colonyforming units (CFU)/mL was dropped onto the surfaces of the melt-blown nonwovens, and a sterilized $50 \mathrm{~mL}$ beaker was placed onto the top of the nonwovens to keep adequate contact of the microbial suspension with the nonwovens. The inoculated controls or the grafted PP melt-blown nonwovens were placed into $100 \mathrm{~mL}$ of distilled water after different contact times. The mixture was shaken vigorously for $10 \mathrm{~min}$. An aliquot of the microbial suspension was removed from the mixture and then serially diluted, and $100 \mu \mathrm{L}$ of each dilution was placed onto a nutrient agar plate and incubated at $37^{\circ} \mathrm{C}$ for $24 \mathrm{~h}$. The bacterial reduction was calculated according to the following equation:

$$
\text { percentage reduction of bacteria }(\%)=\frac{A-B}{B} \times 100,
$$

where $A$ and $B$ are the number of bacteria counted from control and grafted PP melt-blown nonwovens, respectively. In order to investigate the active chlorine loss during the antibacterial test, after $30 \mathrm{~min}$ contact with bacteria, the tested melt-blown nonwovens were washed 3 times with distilled water and dried in vacuum at $40^{\circ} \mathrm{C}$ for $6 \mathrm{~h}$. The iodometric/thiosulfate titration method was used to measure the active chlorine content after the antibacterial test.

\section{Results and Discussion}

3.1. The Effect of Mixing Weight Ratio on Grafting. The effects of the monomer and the initiator content on the grafting effect of NDAM were studied. As mentioned above (equation (1) and (2)), the grafting level of NDAM onto PP was confirmed by the GD and GE results. As shown in Table 1, when the DCP content was set to $0.4 \mathrm{~g}$, the GD results increased from $2.51 \mathrm{wt} . \%$ to $3.34 \mathrm{wt} . \%$ with the increase of NDAM from $8 \mathrm{~g}$ to $10 \mathrm{~g}$. Notably, a similar trend is found for other weight variations of DCP (i.e., 0.5, 0.6, and $0.7 \mathrm{~g}$ ). That is because when the content of DCP was constant, the amount of initial free radicals generated by thermal decomposition was relatively fixed, and increasing the NDAM content could enhance the reaction between NDAM monomer and PP macromolecular radicals, resulting in the increasing GD and GE values of NDAM. However, the concentration of macromolecules generated per unit time was limited when the monomer content reached a specific value, which made GD to increase slowly and GE to decrease. In other words, using too much NDAM could lead to more waste of monomer reactants.

From another point of view, when the content of NDAM was $8 \mathrm{~g}$, the GD increased to a peak value when the weight of DCP was $0.6 \mathrm{~g}$. However, GD decreased with further increase of DCP. A similar tendency could be found for the other weight of NDAM (i.e., 9 and $10 \mathrm{~g}$ ). Moreover, the index of GE has the same tendency as GD when keeping NDAM constant. The results may be due to the simultaneous occurrence of graft polymerization and degradation reaction in the process of reactive extrusion, and the initial free radical concentration produced by thermal decomposition increased with the increase of the DCP content, which enhanced the chance of collision between NDAM monomer and PP macromolecular free radicals. However, the excessive content of the DCP initiator could induce more polymer 
TABLE 1: Composition, grafting degree, and grafting efficiency of modified samples.

\begin{tabular}{lccccc}
\hline Sample code & PP $(\mathrm{g})$ & NDAM $(\mathrm{g})$ & DCP $(\mathrm{g})$ & GD $(w t . \%)$ & GE $(\%)$ \\
\hline A1 & 100 & 8 & 0.4 & 2.51 & 34.03 \\
A2 & 100 & 8 & 0.5 & 3.07 & 41.69 \\
A3 & 100 & 8 & 0.6 & 3.16 & 42.92 \\
A4 & 100 & 8 & 0.7 & 2.91 & 39.85 \\
B1 & 100 & 9 & 0.4 & 2.98 & 37.24 \\
B2 & 100 & 9 & 0.5 & 3.54 & 46.05 \\
B3 & 100 & 9 & 0.6 & 4.61 & 56.13 \\
B4 & 100 & 9 & 0.7 & 4.45 & 53.95 \\
C1 & 100 & 10 & 0.4 & 3.34 & 36.78 \\
C2 & 100 & 10 & 0.5 & 4.01 & 44.39 \\
C3 & 100 & 10 & 0.6 & 4.85 & 53.71 \\
C4 & 100 & 10 & 0.7 & 4.72 & 52.23 \\
\hline
\end{tabular}

degradation, resulting in the reduction of tertiary $\mathrm{C}-\mathrm{H}$ bonds and the decrease of GD and GE. It is obvious to see that the maximum GD was $4.85 \mathrm{wt} . \%$ when the content of NDAM was $10 \mathrm{~g}$ and DCP was $0.6 \mathrm{~g}$, while the maximum GE was $56.13 \%$ when the content of NDAM was $9 \mathrm{~g}$ and DCP was $0.6 \mathrm{~g}$.

The successful graft polymerization for adding NDAM monomer onto PP was confirmed with FTIR spectroscopic analysis. The FTIR spectra of pristine PP and the grafted PP are shown in Figure 4. Compared with the spectrum of the pristine PP, all the grafted materials showed two additional characteristic peaks around 1615 and $1558 \mathrm{~cm}^{-1}$ which were attributed to the bending deformations of amino-azine and the stretching vibration of planar triazine ring, respectively [31]. Given that the unreacted monomer and homopolymers have been removed by the treatment in hot toluene and acetone, the spectra can confirm that the NDAM monomer was successfully grafted onto the PP polymer chains. In addition, the intensity of characteristic peaks increased with an increase in the GD of NDAM monomer.

Figure 5 shows the thermogravimetric analysis of the pristine PP and the grafted PP (samples A3, B3, and C3) with different NDAM contents. The TG curves of the grafted PP samples shifted slightly to a higher temperature, and the temperature of pristine $\mathrm{PP}$ with $10 \%$ thermal weight loss was $415^{\circ} \mathrm{C}$, whereas the temperature raised to $426^{\circ} \mathrm{C}$ for those grafted PP polymers, and the residual mass of the grafted PP was also higher than pristine PP. The TGA results indicated that the thermal stability of the grafted PP polymers had been improved after the grafting process. This phenomenon may be contributed to the triazine ring structure in the NDAM monomer, which could improve the thermal stability of PP.

\subsection{Structure and Filtration Property of the Grafted Melt-} Blown Nonwovens. The sample B3 with the highest grafting efficiency was selected for granulation, and then the obtained PP-g-NDAM and pristine PP resins were thoroughly mixed in different weight ratios to fabricate melt-blown nonwovens with a basic weight of $40 \pm 3 \mathrm{~g} / \mathrm{m}^{2}$. Figure 6 shows the morphologies of the melt-blown nonwovens characterized by SEM. A randomly arranged three-dimensional

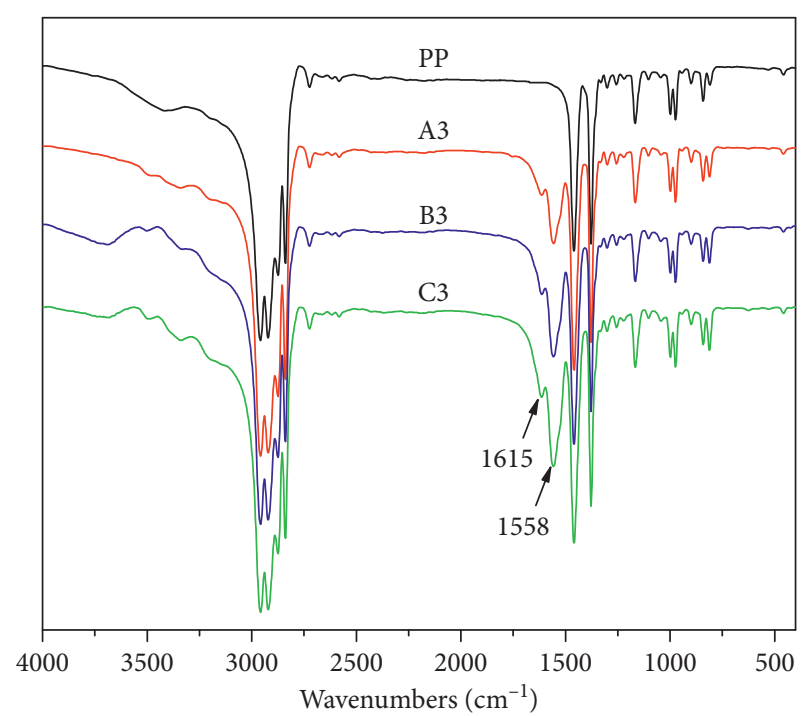

FIgURE 4: FTIR spectra of pristine PP and grafted PP samples prepared with different compositions, $\mathrm{A} 3:[\mathrm{NDAM}]=8 \mathrm{~g}$ and $[\mathrm{DCP}]=0.6 \mathrm{~g}, \mathrm{~B} 3:[\mathrm{NDAM}]=9 \mathrm{~g}$ and $[\mathrm{DCP}]=0.6 \mathrm{~g}$, and $\mathrm{C} 3$ : $[\mathrm{NDAM}]=10 \mathrm{~g}$ and $[\mathrm{DCP}]=0.6 \mathrm{~g}$.

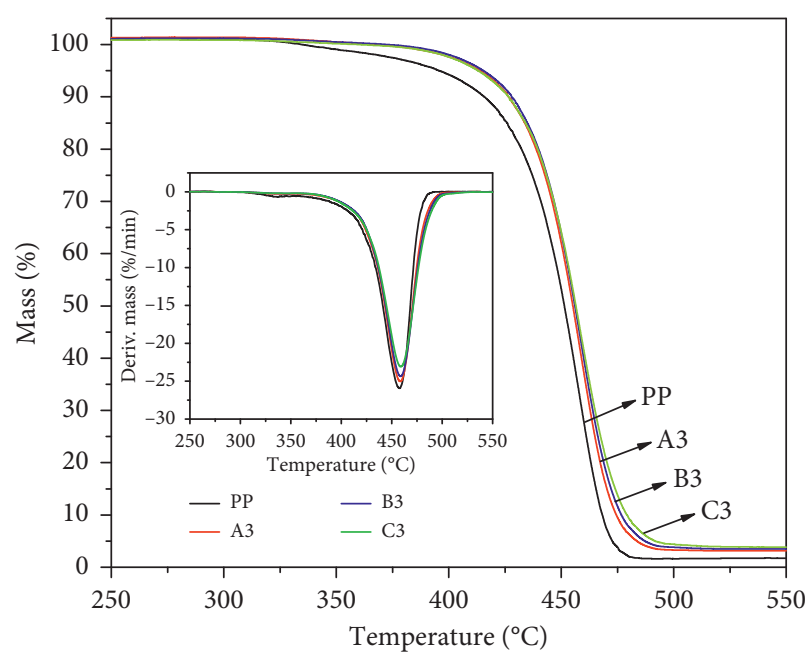

FIGURe 5: TG and DTG (inset) profiles for pristine PP and grafted PP samples prepared with different compositions.

microporous structure could be observed on the received melt-blown nonwovens. Moreover, the large diameter distribution is caused by the unstable attenuating effect of air (airflow is turbulence). Figure 6(a) shows a smooth surface on pristine fibers. However, as shown in Figures 6(b)-6(d), when increasing the concentration of PP-g-NDAM, some spots appeared on the fiber surface.

Figure 6(e) shows the effect of PP-g-NDAM concentration on the diameter of the melt-blown fibers. The fiber diameter was increased from $3.16 \pm 0.65 \mu \mathrm{m}$ to $4.69 \pm 1.39 \mu \mathrm{m}$ with the increase of the concentration of PPg-NDAM. In addition, the concentration of PP-g-NDAM also played a significant role in the pore size distribution of the as-received melt-blown nonwovens. As shown in Figure 6(f), the unimodal pore size distribution was shown 


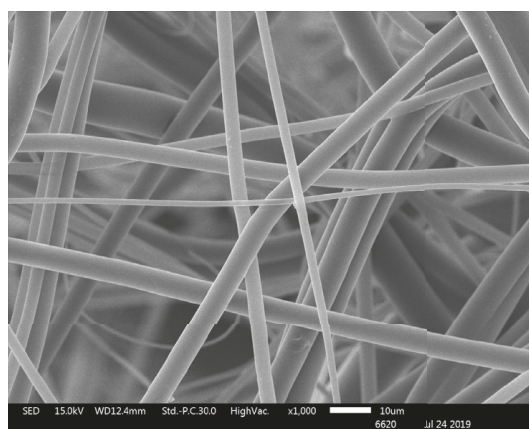

(a)

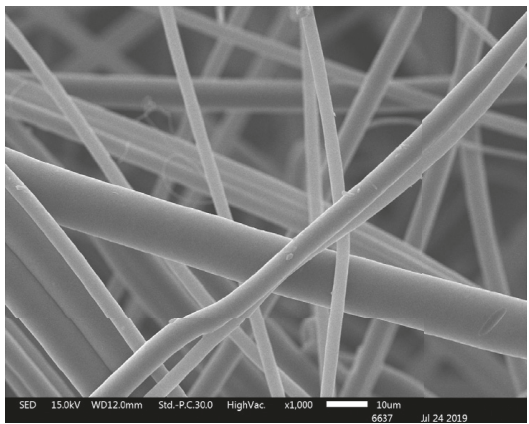

(c)

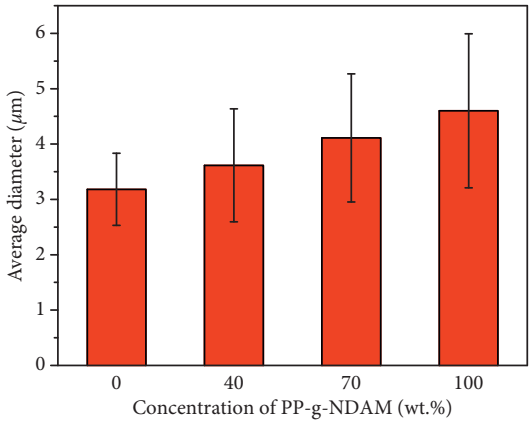

(e)

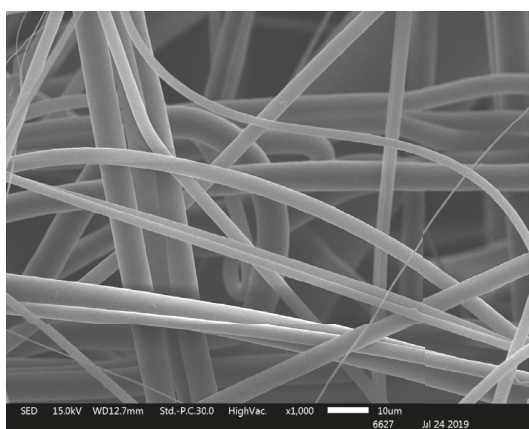

(b)

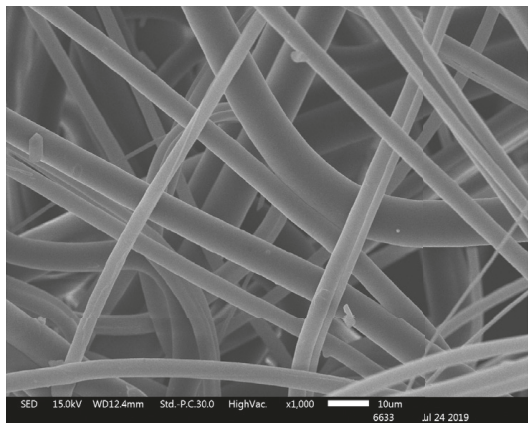

(d)

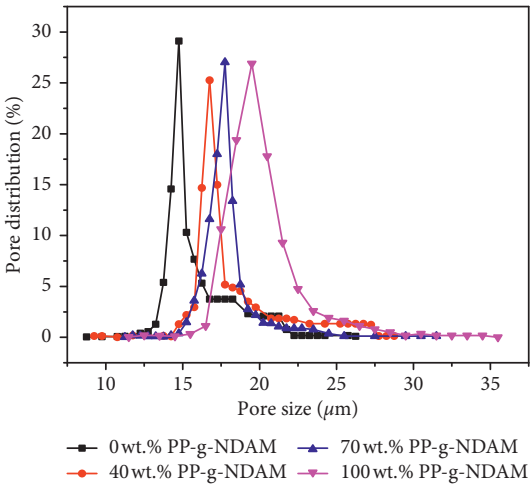

(f)

Figure 6: SEM images of melt-blown nonwovens containing (a) 0 wt.\%, (b) 40 wt.\%, (c) 70 wt.\%, and (d) 100 wt.\% PP-g-NDAM. (e) Fiber average diameter and (f) pore size distribution curves.

in each case, and the peaks shifted in sequence upon an increase in the concentration of PP-g-NDAM. Moreover, the distribution peaks broadened with the increase in the concentration of PP-g-NDAM, which could be attributed to the branching reaction of $\mathrm{PP}$ chains with the introduction of NDAM. Typically, PP macromolecules with long-chain branching lead to an increase in melt viscosity. The high melt viscosity would hinder fiber stretching in the hot-speed drawing process, resulting in an increase of fiber diameter, pore size as well as the number of spots.

In order to assess the capability in air filtration, the filtration efficiency against $\mathrm{NaCl}$ aerosols of the grafted meltblown nonwovens was investigated. Figure 7 (a) shows the filtration efficiency and the pressure drop of the grafted melt-blown nonwovens with different concentrations of PPg-NDAM. It indicates that the process of corona charging is beneficial to improve the filtration performance. After corona charging, the filtration efficiency of $40 \mathrm{wt} \% \mathrm{PP}-\mathrm{g}$ NDAM melt-blown nonwoven dramatically increased from $37.64 \%$ to $85.88 \%$ with no striking change in pressure drop. The electrostatic attraction is responsible for the boost in filtration performance, as the $\mathrm{NaCl}$ aerosols are mostly charged and adsorbed on the fibers when they approached the nonwovens [32, 33]. Figure 7 (a) also shows the same trends in uncharged nonwovens because the filtration efficiency and pressure drop of the grafted nonwovens gradually decreased with the increase in the concentration of PP-gNDAM, which is ascribed to the construction of larger fiber diameters and pore sizes.

Quality factor (QF) is usually used to characterize the filtration performance of filter materials [34-37], and it could be calculated by the following equation: 


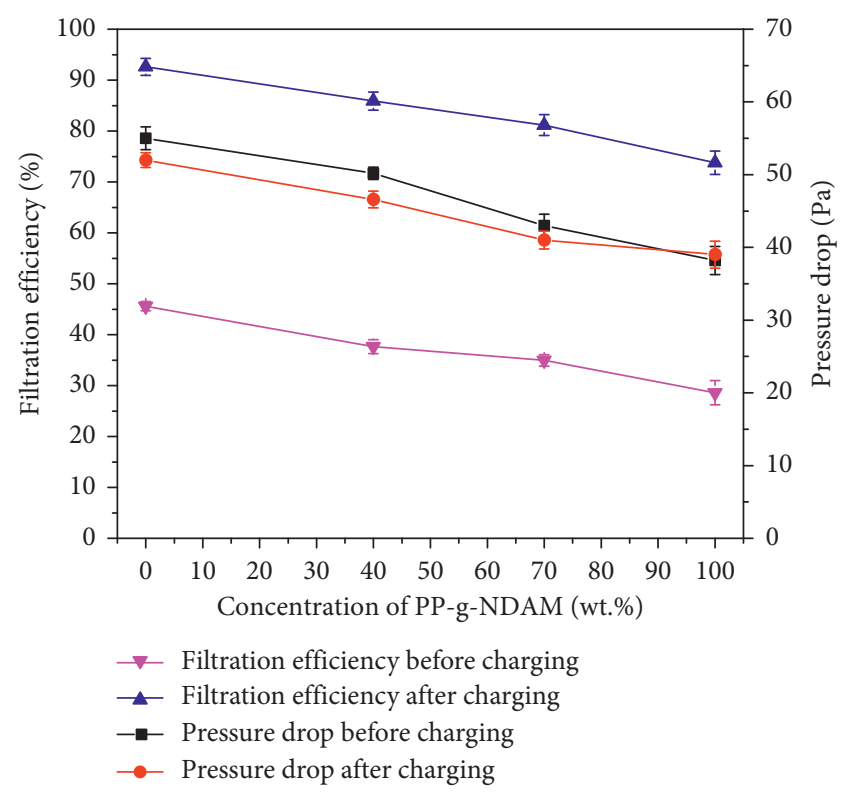

(a)

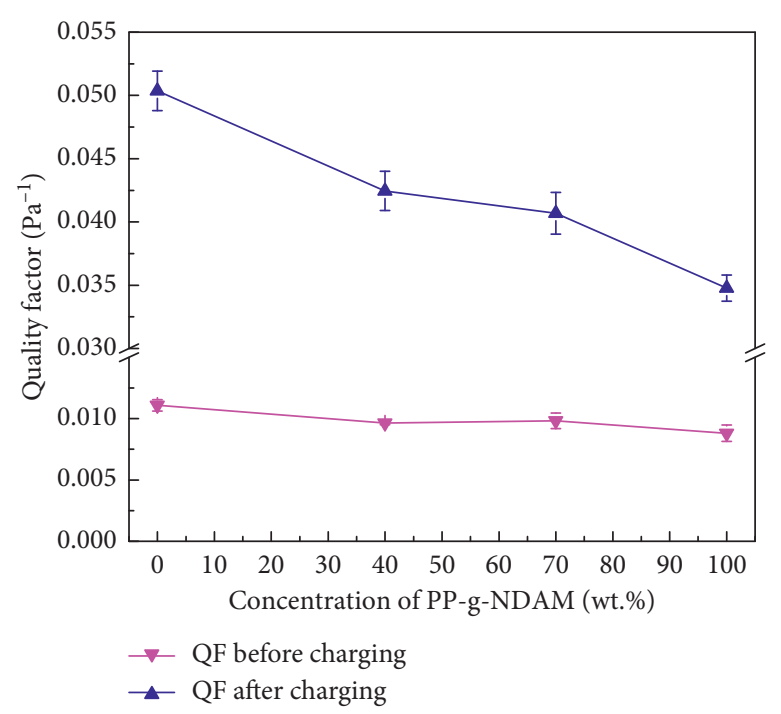

(b)

FIGURE 7: (a) Filtration efficiency and pressure drop and (b) quality factor value of melt-blown nonwovens with different concentrations of PP-g-NDAM.

$$
\mathrm{QF}=-\frac{\ln (1-\eta)}{\Delta p},
$$

where $\eta$ is the filtration efficiency and $\Delta p$ is the pressure drop. As shown in Figure 7(b), the QF values of all samples before corona charging are less than $0.0120 \mathrm{~Pa}^{-1}$ because the filtration efficiency of each sample was relatively low. After charging, the filtration efficiency of each sample significantly increases, whereas the pressure drop remains unchanged; as a result, a high QF value of the target sample is obtained after corona charging treatment. The QF of pristine PP melt-blown nonwoven reaches to $0.0504 \pm 0.0015 \mathrm{~Pa}^{-1}$, and the QF of the modified melt-blown nonwovens decreases gradually with the increase of the PP-g-NDAM concentration, and the QF of 100 wt.\% PP-g-NDAM melt-blown nonwoven reaches to the minimum value, i.e., $0.0348 \pm 0.0011 \mathrm{~Pa}^{-1}$. Besides, Figure 7 further indicates that the corona charging could effectively improve the filtration efficiency of the melt-blown nonwovens without increasing the pressure drop.

3.3. Active Chlorine Content. The content of active chlorine was used to assess the antibacterial ability of the melt-blown nonwovens, and a higher content of the active chlorine indicates a better antibacterial ability of the nonwovens [38]. Figure 8 (a) shows the active chlorine content of melt-blown nonwovens containing 0, 40, 70, and 100 wt.\% PP-g-NDAM after chlorination. It could be seen that no active chlorine was formed on the pristine PP melt-blown nonwovens, even after the chlorination treatment. That is because there is no chemical modification site on PP surface to bind active chlorine, which results in easy wash-off of the unreacted chlorine after chlorination. However, the other melt-blown nonwovens containing PP-g-NDAM exhibited sufficient active chlorine contents. The active chlorine content of the melt-blown nonwovens with the PP-g-NDAM concentration of 40,70, and 100 wt. $\%$ was $0.309 \pm 0.012 \%$ o, $0.409 \pm 0.024 \%$, and $0.463 \pm 0.031 \%$, respectively. It could be found that the content of active chlorine increased with the increase of the PP-gNDAM concentration. This is because the nonwovens containing a higher PP-g-NDAM concentration could provide more $-\mathrm{NH}_{2}$ groups, which is essential for chlorination to form -NHCl (see Scheme 1 and Figure 3). However, the increasing rate of active chlorine slows down with the increase of the PPg-NDAM concentration, and due to the $N$-halamine transformation on the fiber surface, the specific surface area of fibers will be decreased with the average diameter of melt-blown fibers getting larger. It could be also verified from Figure 6(e) that the fiber diameter was increased with the increase of the PP-g-NDAM concentration. Furthermore, in the antibacterial test, after $30 \mathrm{~min}$ the active chlorine content reduced significantly for PP-g-NDAM melt-blown nonwovens (Figure 8(a)). Due to the consumption of active chlorine in the antibacterial process, the active chlorine content is finally decreased to $0.103 \pm 0.007 \%$ o, $0.172 \pm 0.026 \%$, and $0.223 \pm 0.030 \%$ o for 40 wt.\%, 70 wt.\%, and 100 wt.\% PP-g-NDAM melt-blown nonwovens, respectively.

As shown in Figure 8(b), after repeating the reduction and chlorination treatment for 10 times, the active chlorine content of $40 \mathrm{wt} . \%, 70 \mathrm{wt} . \%$, and $100 \mathrm{wt} . \%$ PP-g-NDAM melt-blown nonwovens decreases slightly by 3.35\%, 3.13\%, and $3.08 \%$, respectively, indicating the good regeneration ability of the PP-g-NDAM melt-blown nonwovens. However, with the increase of regeneration times, the active chlorine content in the melt-blown nonwovens will gradually decrease according to the performance after 10 times of cycling (Figure $8(\mathrm{~b})$ ). This may be ascribed to the loss of the grafted antibacterial agent (NDAM) during chlorine 


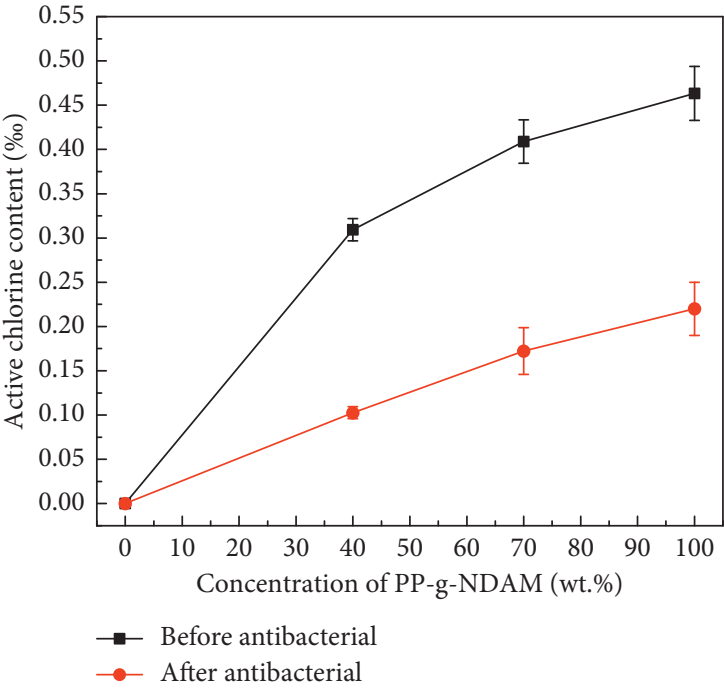

(a)

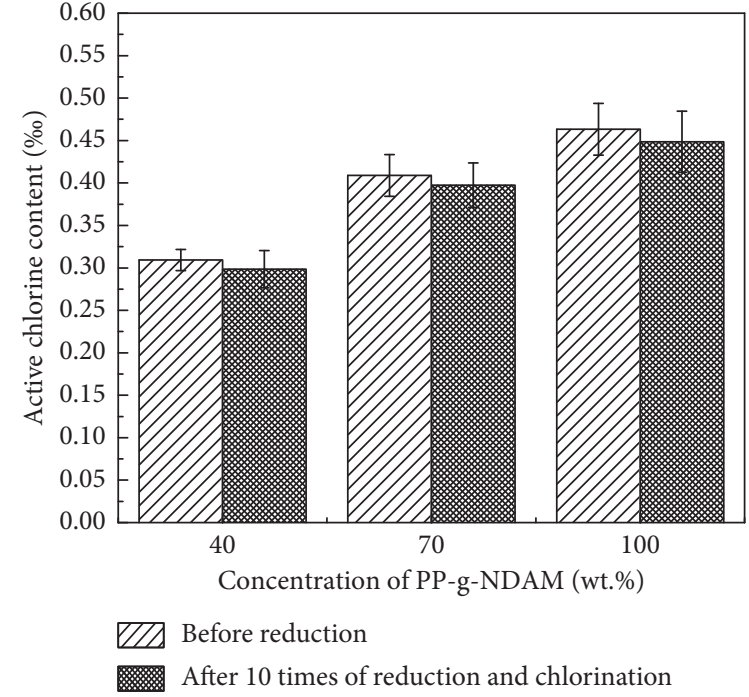

(b)

FIGURE 8: Active chlorine content of chlorinated melt-blown nonwovens with different concentrations of PP-g-NDAM (a) before and after antibacterial treatment and (b) after repeating the reduction and chlorination treatment for 10 times.

TABLe 2: Antibacterial properties of grafted melt-blown samples against E. coli after different contact times.

\begin{tabular}{|c|c|c|c|}
\hline \multirow[t]{2}{*}{ Concentration of PP-g-NDAM (wt.\%) } & \multicolumn{3}{|c|}{$\begin{array}{l}\text { Percentage reduction of } \\
\text { E. coli at different } \\
\text { contact times }(\%)\end{array}$} \\
\hline & $15 \mathrm{~min}$ & $30 \mathrm{~min}$ & $60 \mathrm{~min}$ \\
\hline 40 & 95.35 & 99.99 & 99.999 \\
\hline 70 & 99.99 & 99.999 & 99.999 \\
\hline 100 & 99.99 & 99.999 & 99.999 \\
\hline
\end{tabular}

bleaching treatment, which results in an insufficient regeneration of active chlorine.

3.4. Antibacterial Property of the Grafted Melt-Blown Nonwovens. The antibacterial results of melt-blown nonwovens containing different PP-g-NDAM concentrations are listed in Table 2. The proliferated colonies of E. coli were observed on the pristine PP melt-blown nonwoven, while the grafted melt-blown nonwovens showed excellent antibacterial properties against E. coli. For the nonwovens containing 40 wt.\% PP-g-NDAM, $95.35 \%$ and $99.99 \%$ of the bacteria were sterilized within 15 and $30 \mathrm{~min}$, respectively. For the nonwovens containing 70 wt.\% PP-g-NDAM, 99.99\% of the bacteria were killed just within $15 \mathrm{~min}$. However, the sterilization speed is no longer faster for the $100 \mathrm{wt} \% \mathrm{PP}-\mathrm{g}$-NDAM nonwovens, indicating that $70 \mathrm{wt} \% \mathrm{PP}-\mathrm{g}-\mathrm{NDAM}$ is sufficient for sterilizing the E. coli. Moreover, long-term stability of antibacterial properties was also investigated. After 10 days, the antibacterial properties of the samples show no significant change as all grafted melt-blown nonwovens could sterilize $99.99 \%$ of $E$. coli after a contact time of $30 \mathrm{~min}$.

\section{Conclusions}

NDAM monomer was successfully grafted onto the PP backbone by using radical polymerization during reactive extrusion, which was confirmed by nitrogen analysis and FTIR spectra. Increasing NDAM monomer content could increase the degree of substitution; however, excessive NDAM may result in a decrease in GE. Besides, the GD and GE reached to the maximum value when the weight of DCP was $0.6 \mathrm{~g}$. However, further increase of DCP initiators could result in a decline on GD and GE value. The sample B3 with the highest GE of 4.85 wt.\% was selected to prepare meltblown nonwovens with pristine PP resins in different ratios, and the filtration efficiency of the charged melt-blown nonwovens containing 40, 70, and 100 wt.\% PP-g-NDAM can reach $85.88 \pm 1.77 \%, 81.16 \pm 2.04 \%$, and $73.33 \pm 2.29 \%$ with low resistance, respectively. The chlorinated melt-blown samples containing 70 and 100 wt.\% PP-g-NDAM exhibited potent antibacterial properties against $E$. coli bacterium after 15 min contact time. Thus, the grafted melt-blown nonwovens may become a good candidate for personal protective filtration materials with antibacterial properties. Further investigation can be done in the improvement of filtration performance by reducing fiber diameters and increasing specific surface areas of the bifunctional nonwoven filters. At the same time, the mechanism studies on the regeneration of active chlorine content and antibacterial properties after chlorine bleaching should be investigated.

\section{Data Availability}

The data used to support the findings of this study are available from the corresponding author upon request. 


\section{Conflicts of Interest}

The authors declare that they have no conflicts of interest.

\section{Acknowledgments}

This work was supported by the Ph.D. Graduate Innovation Fund Project of Donghua University (102552016015) and Scientific Research Project from Education Department of Hunan Province of China (18C0693).

\section{References}

[1] N. Zhao and S. Liu, "Thermoplastic semi-IPN of polypropylene (PP) and polymeric $N$-halamine for efficient and durable antibacterial activity," European Polymer Journal, vol. 47, no. 8, pp. 1654-1663, 2011.

[2] N. Zhao, G. G. Zhanel, and S. Liu, "Regenerability of antibacterial activity of interpenetrating polymeric $N$-halamine and poly (ethylene terephthalate)," Journal of Applied Polymer Science, vol. 120, no. 1, pp. 611-622, 2011.

[3] S. Liu, N. Zhao, and S. Rudenja, "Surface interpenetrating networks of poly (ethylene terephthalate) and polyamides for effective biocidal properties," Macromolecular Chemistry and Physics, vol. 211, no. 3, pp. 286-296, 2010.

[4] B. Demir, I. Cerkez, S. D. Worley, R. M. Broughton, and T.-S. Huang, "N-halamine-modified antimicrobial polypropylene nonwoven fabrics for use against airborne bacteria," ACS Applied Materials \& Interfaces, vol. 7, no. 3, pp. 1752-1757, 2015.

[5] F. Hui and C. Debiemme-Chouvy, "Antimicrobial $N$-halamine polymers and coatings: a review of their synthesis, characterization, and applications," Biomacromolecules, vol. 14, no. 3, pp. 585-601, 2013.

[6] Z. Ma, M. Yin, M. Zhang, Z. Qi, X. Ren, and T.-S. Huang, "Durable $N$-halamine antibacterial cellulose based on thiolene click chemistry," Fibers and Polymers, vol. 20, no. 2, pp. 244-249, 2019.

[7] A. D. Rohr, L. J. Bastarrachea, and J. M. Goddard, "Antimicrobial efficacy of $N$-halamine coatings prepared via dip and spray layer-by-layer deposition," Food and Bioproducts Processing, vol. 96, pp. 12-19, 2015.

[8] E.-R. Kenawy, S. D. Worley, and R. Broughton, "The chemistry and applications of antimicrobial polymers: a stateof-the-art review," Biomacromolecules, vol. 8, no. 5, pp. 1359-1384, 2007.

[9] L. Li, T. Pu, G. Zhanel, N. Zhao, W. Ens, and S. Liu, "New biocide with both $\mathrm{N}$-chloramine and quaternary ammonium moieties exerts enhanced bactericidal activity," Advanced Healthcare Materials, vol. 1, no. 5, pp. 609-620, 2012.

[10] J. Zhu, Q. Bahramian, P. Gibson, H. Schreuder-Gibson, and G. Sun, "Chemical and biological decontamination functions of nanofibrous membranes," Journal of Materials Chemistry, vol. 22, no. 17, pp. 8532-8540, 2012.

[11] Y. Liu, Q. He, R. Li, D. Huang, X. Ren, and T.-S. Huang, "Durable antimicrobial cotton fabrics treated with a novel $N$ halamine compound," Fibers and Polymers, vol. 17, no. 12, pp. 2035-2040, 2016.

[12] Y. Sun and G. Sun, "Novel regenerable $N$-halamine polymeric biocides. III. grafting hydantoin-containing monomers onto synthetic fabrics," Journal of Applied Polymer Science, vol. 81, no. 6, pp. 1517-1525, 2001.
[13] Y. Gao and R. Cranston, "Recent advances in antimicrobial treatments of textiles," Textile Research Journal, vol. 78, no. 1, pp. 60-72, 2008.

[14] M. B. Dickerson, W. Lyon, W. E. Gruner, P. A. Mirau, J. M. Slocik, and R. R. Naik, "Sporicidal/bactericidal Textiles via the chlorination of silk," ACS Applied Materials \& Interfaces, vol. 4, no. 3, pp. 1724-1732, 2012.

[15] M. R. Badrossamay and G. Sun, "Acyclic halamine polypropylene polymer: effect of monomer structure on grafting efficiency, stability and biocidal activities," Reactive and Functional Polymers, vol. 68, no. 12, pp. 1636-1645, 2008.

[16] M. R. Badrossamay and G. Sun, "Graft polymerization of N-tert-butylacrylamide onto polypropylene during melt extrusion and biocidal properties of its products," Polymer Engineering \& Science, vol. 49, no. 2, pp. 359-368, 2009.

[17] M. R. Badrossamay and G. Sun, "Durable and rechargeable biocidal polypropylene polymers and fibers prepared by using reactive extrusion," Journal of Biomedical Materials Research Part B: Applied Biomaterials, vol. 89B, no. 1, pp. 93-101, 2009.

[18] D. Wang, N. Liu, W. Xu, and G. Sun, "Layer-by-layer structured nanofiber membranes with photoinduced selfcleaning functions," The Journal of Physical Chemistry C, vol. 115, no. 14, pp. 6825-6832, 2011.

[19] D. Wang and G. Sun, "Formation and morphology of cellulose acetate butyrate (CAB)/polyolefin and $\mathrm{CAB} /$ polyester in situ microfibrillar and lamellar hybrid blends," European Polymer Journal, vol. 43, no. 8, pp. 3587-3596, 2007.

[20] P. Sardashti, C. Tzoganakis, M. A. Polak, and A. Penlidis, "Radiation induced long chain branching in high-density polyethylene through a reactive extrusion process," Macromolecular Reaction Engineering, vol. 8, no. 2, pp. 100-111, 2014.

[21] M. A. Hassan, B. Y. Yeom, A. Wilkie, B. Pourdeyhimi, and S. A. Khan, "Fabrication of nanofiber meltblown membranes and their filtration properties," Journal of Membrane Science, vol. 427, pp. 336-344, 2013.

[22] X. Li, N. Wang, G. Fan et al., "Electreted polyetherimide-silica fibrous membranes for enhanced filtration of fine particles," Journal of Colloid and Interface Science, vol. 439, pp. 12-20, 2015.

[23] M. R. Badrossamay and G. Sun, "A study of radical graft copolymerization on polypropylene during extrusion using two peroxide initiators," Polymer International, vol. 59, no. 2, pp. 155-161, 2010.

[24] J. H. Tian, W. Yu, and C. X. Zhou, "The preparation and rheology characterization of long chain branching polypropylene," Polymer, vol. 47, no. 7, pp. 7962-7969, 2006.

[25] Z. Dai, J. Su, X. Zhu et al., "Multifunctional polyethylene (PE)/ polypropylene (PP) bicomponent fiber filter with anchored nanocrystalline $\mathrm{MnO}_{2}$ for effective air purification," Journal of Materials Chemistry A, vol. 6, no. 30, pp. 14856-14866, 2018.

[26] H. B. Kocer, S. D. Worley, R. M. Broughton, and T. S. Huang, "A novel $N$-halamine acrylamide monomer and its copolymers for antimicrobial coatings," Reactive and Functional Polymers, vol. 71, no. 5, pp. 561-568, 2011.

[27] A. E.-S. I. Ahmed, J. N. Wardell, A. E. Thumser et al., "Metabolomic profiling can differentiate between bactericidal effects of free and polymer bound halogen," Journal of Applied Polymer Science, vol. 119, no. 2, pp. 709-718, 2011.

[28] X. H. Ren, L. Kou, H. B. Kocer et al., "Antimicrobial coating of an $N$-halamine biocidal monomer on cotton fibers via admicellar polymerization," Colloids and Surfaces A: Physicochemical and Engineering Aspects, vol. 317, no. 1-3, pp. 711-716, 2008. 
[29] X. Ren, H. B. Kocer, S. D. Worley, R. M. Broughton, and T. S. Huang, "Rechargeable biocidal cellulose: synthesis and application of 3-(2,3-dihydroxypropyl)-5,5-dimethylimidazolidine-2,4-dione," Carbohydrate Polymers, vol. 75, no. 4, pp. 683-687, 2009.

[30] C. N. Cutter, J. L. Willett, and G. R. Siragusa, "Improved antimicrobial activity of nisin-incorporated polymer films by formulation change and addition of food grade chelator," Letters in Applied Microbiology, vol. 33, no. 4, pp. 325-328, 2001.

[31] Z. Chen and Y. Sun, "Antimicrobial polymers containing melamine derivatives. II. biocidal polymers derived from 2vinyl-4,6-diamino-1,3,5-triazine," Journal of Polymer Science Part A: Polymer Chemistry, vol. 43, no. 18, pp. 4089-4098, 2005.

[32] J. H. Ji, G. N. Bae, S. H. Kang, and J. Hwang, "Effect of particle loading on the collection performance of an electret cabin air filter for submicron aerosols," Journal of Aerosol Science, vol. 34, no. 11, pp. 1493-1504, 2003.

[33] H. Zhang, J. Liu, X. Zhang, C. Huang, and X. Jin, "Design of electret polypropylene melt blown air filtration material containing nucleating agent for effective PM2.5 capture," RSC Advances, vol. 8, no. 15, pp. 7932-7941, 2018.

[34] Y. Yang, S. Zhang, X. Zhao, J. Yu, and B. Ding, "Sandwich structured polyamide-6/polyacrylonitrile nanonets/bead-onstring composite membrane for effective air filtration," Separation and Purification Technology, vol. 152, pp. 14-22, 2015.

[35] B. Liu, S. Zhang, X. Wang, J. Yu, and B. Ding, "Efficient and reusable polyamide-56 nanofiber/nets membrane with bimodal structures for air filtration," Journal of Colloid and Interface Science, vol. 457, pp. 203-211, 2015.

[36] J. Liu, X. Zhang, H. Zhang et al., "Low resistance bicomponent spunbond materials for fresh air filtration with ultra-high dust holding capacity," RSC Advances, vol. 7, no. 69, pp. 4387943887, 2017.

[37] C.-H. Hung and W. W.-F. Leung, "Filtration of nano-aerosol using nanofiber filter under low Peclet number and transitional flow regime," Separation and Purification Technology, vol. 79, no. 1, pp. 34-42, 2011.

[38] D. Wang, W. Xu, G. Sun, and B.-S. Chiou, "Radical graft polymerization of an allyl monomer onto hydrophilic polymers and their antibacterial nanofibrous membranes," ACS Applied Materials \& Interfaces, vol. 3, no. 8, pp. 2838-2844, 2011. 

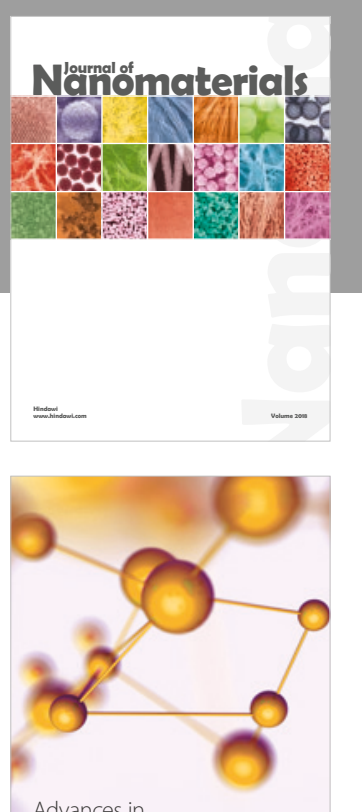

Physical Chemistry
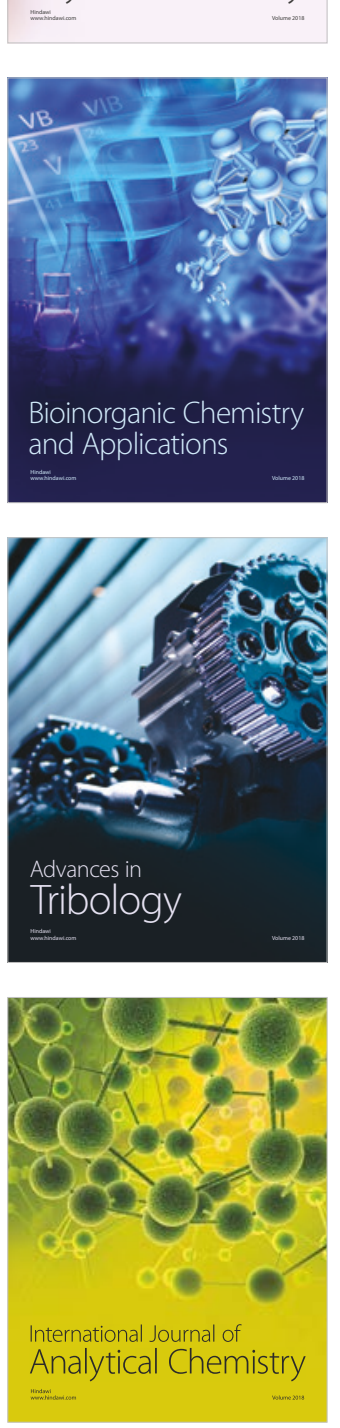

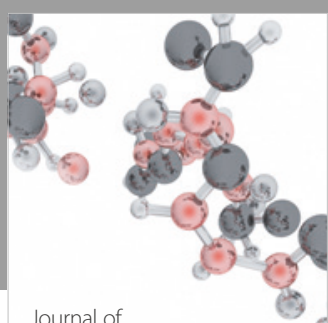

Analytical Methods

in Chemistry

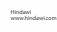

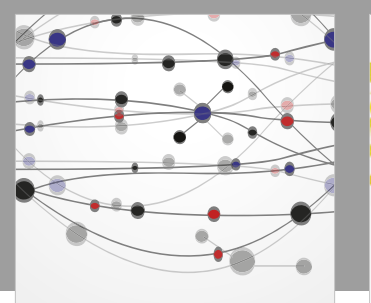

The Scientific World Journal

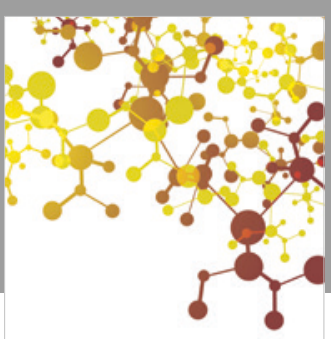

Journal of

Applied Chemistry
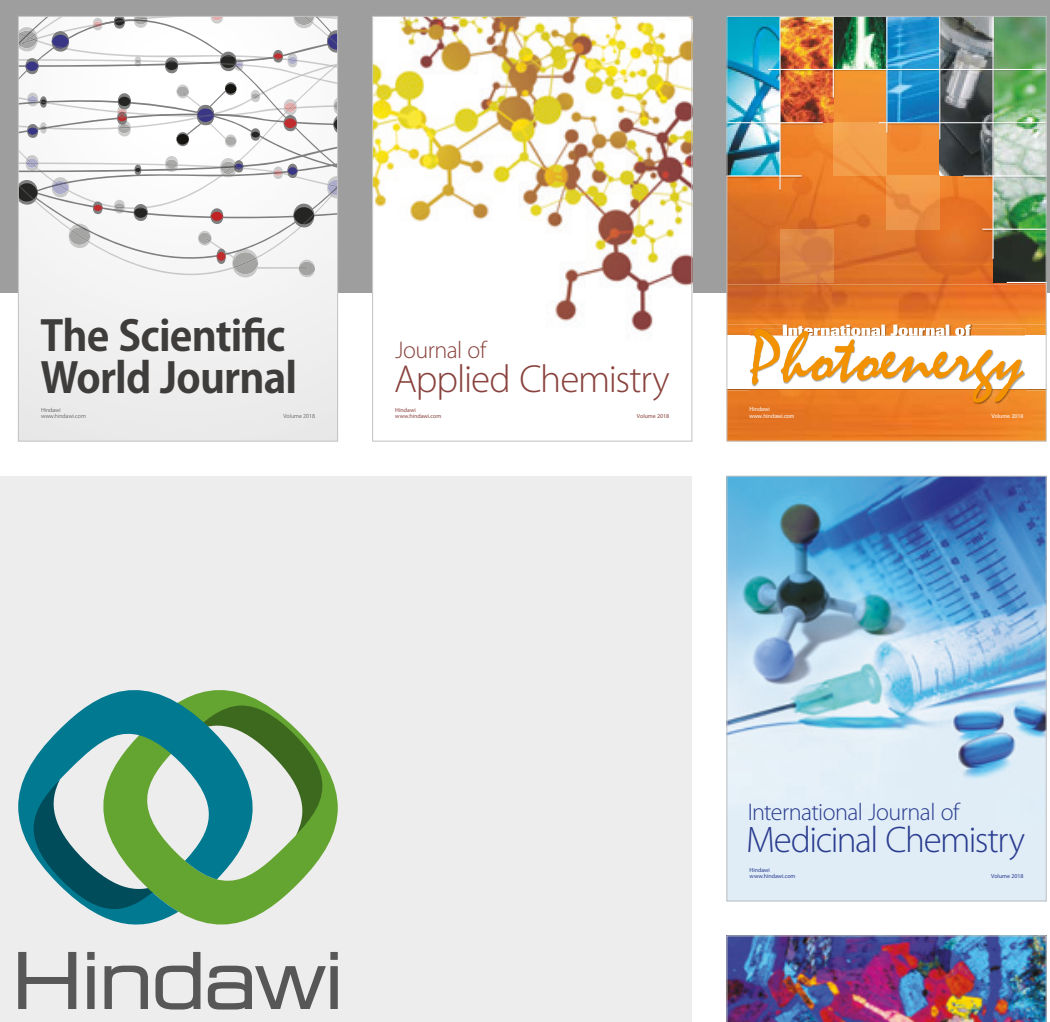

Submit your manuscripts at

www.hindawi.com
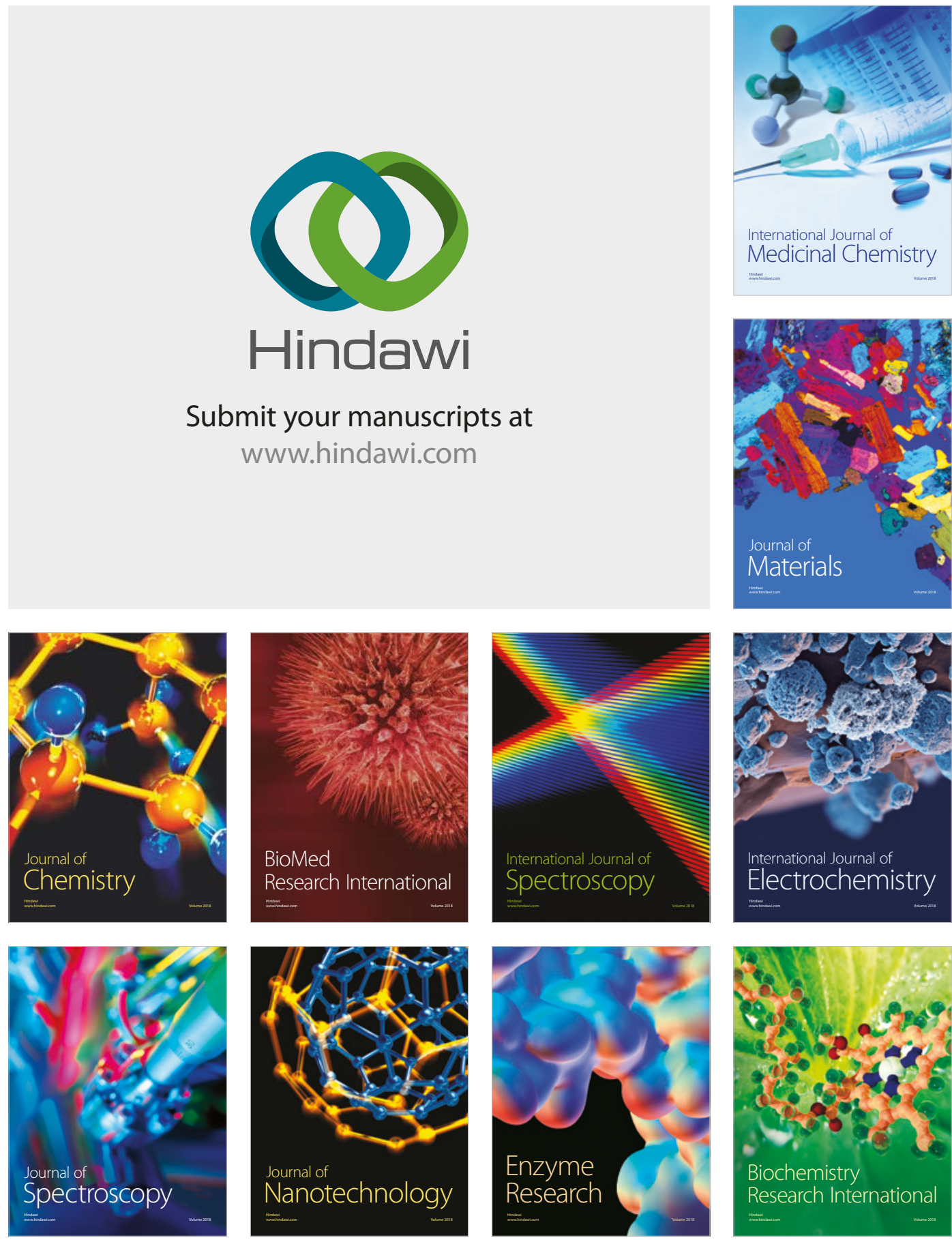
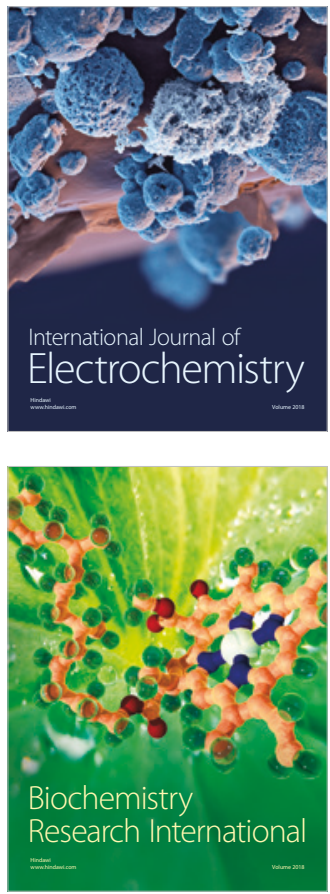